\title{
Relief of sleep apnoea after treatment of acromegaly: report of three cases and review of the literature
}

\author{
B. Buyse*, E. Michiels*, R. Bouillon**, H. Bobbaers+, M. Demedts*
}

\begin{abstract}
Relief of sleep apnoea after treatment of acromegaly: report of three cases and review of the literature. B. Buyse, E. Michiels, R. Bouillon, H. Bobbaers, M. Demedts. (CERS Journals Ltd 1997.

ABSTRACT: Sleep apnoea syndrome (SAS) is common in acromegalic patients. Occasionally, the relief of apnoeas after treatment of the acromegaly has been documented. We report the cases of three patients with acromegaly and severe obstructive sleep apnoea, who demonstrated a manifest improvement (respiratory disturbance index (RDI) <20) after treatment with octreotide, indicating that this drug may be effective in this disturbance.

In one case, SAS disappeared although the growth hormone level was not fully normalized. This raises the intriguing hypothesis that octreotide has an effect on respiratory control or on the upper airway, that is not directly related to its action on production of growth hormone.

Eur Respir J 1997; 10: 1401-1404.
\end{abstract}

*Division of pneumology, **Division of endocrinology, and +Division of internal medicine, University Hospital Gasthuisberg, Catholic University Leuven, Belgium.

Correspondence: B. Buyse

University Hospital Gasthuisberg

Division of pneumology

Herestraat 49

B-3000 Leuven

Belgium

Keywords: Acromegaly, octreotide, polysomnography, respiratory disturbance index, sleep apnoea

Received: April 251996

Accepted after revision November 291996
Sleep apnoea syndrome (SAS) is common in acromegalic patients. The aetiology is upper airway obstruction in two thirds of cases, and is of central nervous origin in one third $[1,2]$. Other factors, including hormonal influence on the respiratory control centre, may be involved. Improvement of SAS following treatment for acromegaly (with octreotide, bromocriptine, adenomectomy and/or radiotherapy) has been documented in several publications [3-11].

We report the cases of three acromegalic patients with SAS which improved after treatment of their acromegaly. We emphasize the clear-cut favourable influence of octreotide on the degree of SAS. We also review the literature concerning objective polygraphic amelioration of the SAS after treating the acromegaly.

\section{Materials and methods}

\section{Sleep studies}

Patients underwent overnight sleep studies in our sleep laboratory. Polysomnography consisted of electroencephalogram, electro-oculogram, electrocardiogram, electromyogram, chest wall and abdominal plethysmogram, oronasal airflow monitoring, and continuous registration of transcutaneous oxygen. To assess the severity of sleep apnoea, the following indices were measured: number of apnoeas (absence of airflow during $\geq 10 \mathrm{~s}$ ); number of hypopnoeas (reduction of airflow by $50 \%$ during $\geq 10$ s with at least $4 \%$ desaturation); respiratory disturbance index (RDI), i.e. number of apnoeas and hypopnoeas per hour of sleep; mean transcutaneous oxygen saturation; minimum transcutaneous oxygen saturation; and duration of desaturation (\% of total sleep time with transcutaneous oxygen saturation $\left.\left(S \mathrm{tc}, \mathrm{O}_{2}\right)<90 \%\right)$. Sleep efficiency, percentage rapid eye movement (REM) and slow wave sleep were also assessed.

\section{Measurements of the endocrine status}

Serum growth hormone $(\mathrm{GH})$ and somatomedin C levels were determined using a radioimmunoassay (RIA) method (normal serum $\mathrm{GH}<7.5 \mathrm{ng} \cdot \mathrm{mL}^{-1}$; normal somatomedin $\left.\mathrm{C}<300 \mathrm{ng} \cdot \mathrm{mL}^{-1}\right)$.

\section{Case reports (table 1)}

\section{Case No. 1}

A $68 \mathrm{yr}$ old man presented with daytime hypersomnolence. He manifested acral growth. The fasting serum $\mathrm{GH}$ and somatomedin $\mathrm{C}$ levels were markedly raised. A radiographic image of the skull demonstrated a pituitary tumour. At polysomnography, a severe obstructive SAS was diagnosed. The apnoeas and hypopnoeas were treated with nasal continuous positive airway pressure (nCPAP). The acromegaly was treated with octreotide, $400 \mu \mathrm{g} \cdot \mathrm{day}^{-1}$.

After a total treatment period of 1 year, the patient was re-evaluated. His GH level was not fully suppressed, but somatomedin $\mathrm{C}$ had normalized. He no longer reported hypersomnolence. The nCPAP was stopped and a control polysomnography was performed some days later (whilst the patient was still receiving octreotide): a RDI of only 7 episodes $\cdot \mathrm{h}^{-1}$ was recorded. The 


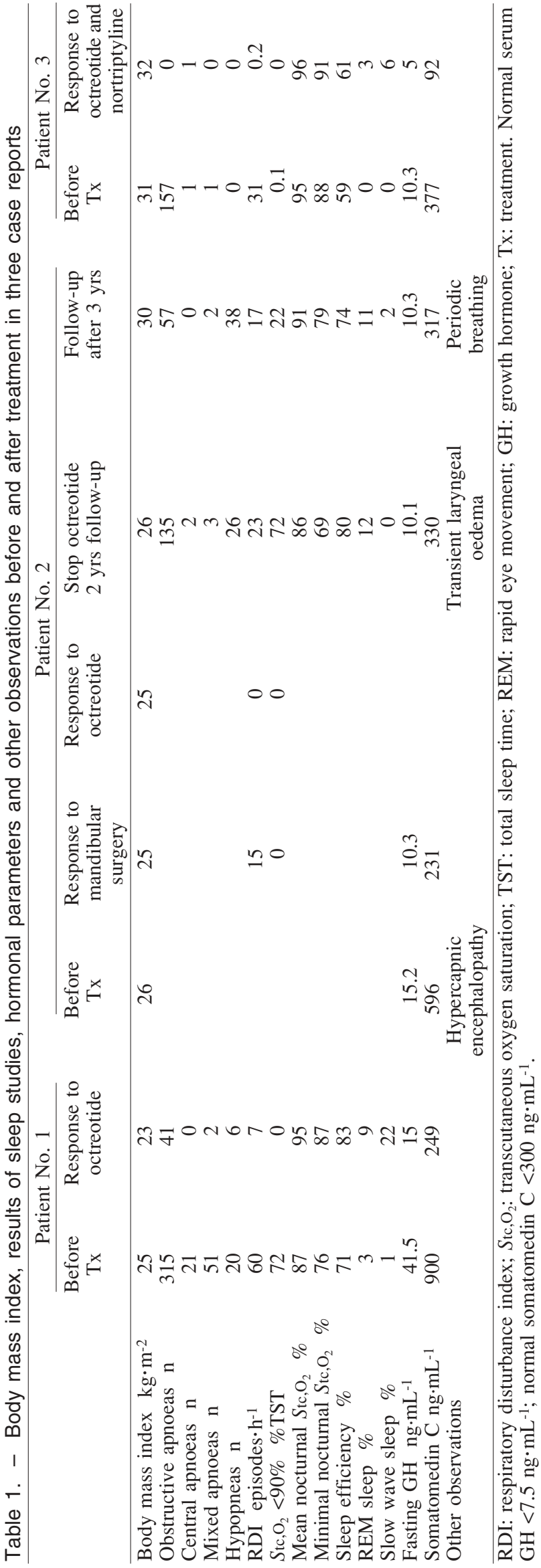

nCPAP treatment was no longer applied but octreotide $400 \mathrm{mg} \cdot \mathrm{day}^{-1}$, was continued, with good clinical results so far.

\section{Case No. 2}

A 45 year old man was urgently referred to the intensive care unit with hypercapnic encephalopathy ( $\mathrm{pH} 7.05$, arterial carbon dioxide tension $\left.\left(\mathrm{Pa}_{\mathrm{a}} \mathrm{CO}_{2}\right)(144 \mathrm{mmHg})\right)$. Immediate intubation and artificial ventilation was necessary. His acromegaly had been diagnosed 6 yrs previously and was treated with pituitary adenomectomy followed by radiotherapy $50 \mathrm{~Gy}$. The patient's family reported that he had snored heavily during the past year. More recently he repeatedly fell asleep during the day. Weaning from the ventilator was only possible after tracheostomy. A pulmonary function investigation with temporary occlusion of the tracheostomy showed severe variable extrathoracic upper airway obstruction: a forced expiratory volume in one second (FEV1) of $4.4 \mathrm{~L}(89 \%$ predicted), and a forced inspiratory volume in one second (FIV1) of only $0.6 \mathrm{~L}$ (15\% pred FEV1). Fasting GH and somatomedin $\mathrm{C}$ levels were elevated. It was decided to operate; and a hyoidopexy, partial glossectomy and mandibular osteotomy was performed, with closure of the tracheostomy some days later.

Three months after surgery, the FIV1 was 1.1 L. Fasting $\mathrm{GH}$ remained slightly elevated, but somatomedin $\mathrm{C}$ value had normalized. The patient still reported problems of fatigue. Because a polysomnographic study could not be performed at that time, the patient was tested overnight using a continuous transcutaneous oxygen saturation meter and continuous airflow measurements. Although no oxygen desaturation was present, the apnoea index was moderately elevated (15 episodes $\left.\cdot \mathrm{h}^{-1}\right)$. Because a residual pituitary tumour was visible on nuclear magnetic resonance (NMR) imaging of the skull in combination with biochemical features of acromegaly, treatment with octreotide, $150 \mu \mathrm{g} \cdot \mathrm{day}^{-1}$, was prescribed.

Two months later, no biochemical evidence of acromegaly, or sleep-related respiratory disturbances (using the same simple recording method as 2 months ago) were found. The patient ceased octreotide treatment after 5 months and refused follow-up.

Two years later, the patient presented again with major complaints of diurnal hypersomnolence and recently developed stridor. There was marked oedema of the larynx and paresis of the left vocal cord. Somatomedin C and fasting GH levels were borderline elevated. On polysomnography, the RDI was increased and nocturnal desaturation was prominent, with drops to $69 \%$. Because of the marked oedema of the larynx, corticosteroids were prescribed for some weeks resulting in disappearance of the stridor. Again, the patient disappeared from follow-up.

After 3 yrs, it was possible to perform a control polysomnography. Although the patient did not complain of hypersomnolence, the test was abnormal, demonstrating periodic breathing with mixed and obstructive apnoeas and hypopnoeas, oxygen desaturation and a substantial number of sleep arousals (47 arousals $\cdot \mathrm{h}^{-1}$ of sleep). The laryngeal oedema had disappeared, while the paresis of the left vocal cord remained. Somatomedin C and fasting GH levels remained borderline elevated. Discussions 
are underway with the endocrinology department on whether to resume octreotide treatment.

Case No. 3

An obese man, 72 yrs of age, presented with snoring and disturbed sleep. Acromegaly had been diagnosed approximately 40 yrs previously, and the treatment had consisted of radiotherapy, followed by bromocriptine. Because of hypotension, bromocriptine had been stopped and octreotide initiated 4 yrs previously, but the patient had interrupted his treatment $1 \mathrm{yr}$ ago. At entry, the fasting $\mathrm{GH}$ and somatomedin $\mathrm{C}$ levels were slightly elevated. A manifest obstructive SAS was detected on polysomnography. Treatment with octreotide was restarted and because a nCPAP trial for sleep apnoea was not tolerated, nortriptyline was prescribed .

After using this medication for 3 months, a re-evaluation was performed. The patient was still obese but clinically much more alert during the daytime. His $\mathrm{GH}$ level had become normal and even his somatomedin $\mathrm{C}$ was low. A new polysomnography demonstrated no breathing disturbance.

\section{Discussion}

We describe three acromegalic patients, who demonstrated symptoms (disturbed sleep, hypersomnolence and hypercapnic encephalopathy) and polysomnographic findings of a severe apnoea problem. In addition, we noted that treatment of their acromegaly by octreotide resulted in a substantial relief of the apnoeas, with a reduction of the RDI to $<20$ episodes $\cdot h^{-1}$.

The frequency of sleep apnoea in acromegaly has been documented in a large scale sleep study showing a frequency of $60 \%$ [1]. Sleep apnoea in acromegaly can be due to obstruction by tissue hypertrophy, macroglossia, and jaw deformity [2]. Other authors have reported central apnoeas and respiratory control centre dysfunction $[1,12]$.
We found eight studies [3, 4, 6-11] reporting the cases of 27 acromegalic patients, who were re-evaluated after treatment (table 2). In two of these studies [3, 4], RDI was not mentioned, but we consider that a RDI $>20$ (similar to that in the other studies) was probable, because the apnoeic duration was at least $27 \%$. In these publications [3, 4, 6-11], 10 of the 27 patients demonstrated a RDI $<20$ after treatment of their acromegaly: three after adenomectomy (in one patient in combination with bromocriptine administration), and seven after octreotide treatment.

We have now added the cases of a further three patients, with at least a temporarily resolved apnoea problem, to this list (table 1), and all three were treated with octreotide. The reduction in apnoeas was not related to prominent weight reduction. Patient No. 1 was treated with octreotide in combination with nCPAP, resulting in disappearance of the severe SAS. Because it is established that nCPAP alone does not ameliorate obstructive SAS [13], octreotide appears the only possible mechanism. In case No. 2, cessation of octreotide was followed by periodic breathing and marked obstructive events (at the time the pharyngeal oedema was prominent). In case No. 3, combination therapy with octreotide and protriptyline resolved the apnoea problem. From the literature, there are indications that the manifest reduction in RDI is not mainly due to nortriptyline; doubleblind, placebo-controlled studies using this medication have shown only marginal or no efficacy in apnoea reduction [14].

The relationship between sleep apnoea and the biochemical activity of acromegaly is not clear. GRUNSTEIN et al. [1] found no correlation between $\mathrm{GH}$ levels and severity of sleep apnoea in 53 patients. Other authors have reported sleep apnoeas in acromegalic patients with a low or normal GH (under therapy) $[15,16]$. In the publications already mentioned [3, 4, 6-11], we also noted three patients with normal GH values after treatment, but with RDI remaining $>20$. An irreversible degree of obstructive sleep apnoea may be caused by fixed hypertrophy and fibrosis of the pharyngeal mucosa and even jaw deformity; these irreversible structural changes might

Table 2. - Data from literature on patients with RDI >20 prior to treatment, re-evaluated after treatment

\begin{tabular}{|c|c|c|c|c|c|c|c|c|}
\hline \multirow{2}{*}{$\begin{array}{l}\text { First } \\
\text { author }\end{array}$} & \multirow[t]{2}{*}{ [Ref.] } & \multicolumn{3}{|c|}{ Before treatment } & \multirow{2}{*}{$\begin{array}{l}\text { Treatment } \\
\text { modality }\end{array}$} & \multicolumn{3}{|c|}{ After treatment } \\
\hline & & $\begin{array}{c}\text { Growth hormone } \\
\text { ng. } \mathrm{mL}^{-1}\end{array}$ & RDI & $\begin{array}{c}\text { apnoeic time } \\
\% \text { total sleep time }\end{array}$ & & $\begin{array}{c}\text { Growth hormone } \\
\text { ng } \cdot \mathrm{mL}^{-1}\end{array}$ & RDI & $\begin{array}{c}\text { apnoeic time } \\
\% \text { total sleep time }\end{array}$ \\
\hline Chanson & [3] & 25 & $?$ & 27 & Oct & 2 & $?$ & 18 \\
\hline ZIEMER & [4] & Elevated & ? & 48 & Bro & Lowered & ? & 12 \\
\hline ESNAULT & [6] & $?$ & 28 & $?$ & Ad, Bro & $?$ & 0.4 & $?$ \\
\hline O'HARE & [7] & Elevated & Severe & SAS & Oct & Lowered & \multicolumn{2}{|c|}{ Dramatic improvement } \\
\hline GRUNSTEIN & [8] & 39.8 & $39 *$ & $27.6^{*}$ & Oct & 9.1 & $19^{*+}$ & $15.1^{*+}$ \\
\hline \multirow[t]{5}{*}{ MiCKELSON } & [9] & 43.9 & 67 & $?$ & PPP, RT, Ad & 3.1 & 24 & $?$ \\
\hline & & 20.2 & 57 & $?$ & UPPP, Ton & 10 & Died & Died \\
\hline & & 50.0 & 49 & ? & Ad, Bro & 2.8 & 12 & $?$ \\
\hline & & Elevated & 73 & ? & Ad, Oct & 9 & 73 & ? \\
\hline & & Elevated & 59 & $?$ & Ad & Normal & 1 & ? \\
\hline \multirow[t]{2}{*}{ Rosenow } & [10] & 20 & 59 & $?$ & Ad, Oct & 3 & 40 & ? \\
\hline & & 31 & 55 & $?$ & Ad & 1.7 & 50 & ? \\
\hline \multirow[t]{2}{*}{ LEIBOWITZ } & [11] & 52.9 & 30 & 16 & Oct & 11.7 & 12 & 8 \\
\hline & & 9.5 & 57 & 79 & Oct & 2.3 & 43 & 59 \\
\hline
\end{tabular}

Five studies $([6-9,11])$ recorded RDI $<20$ after treatment. *: values of 19 patients tested (one without sleep apnoea syndrome (SAS), 4 with RDI 5-10, and 14 with RDI $>30$ ); +: 5 patients of the 14 with RDI $>30$ before, demonstrated RDI $<20$ after treatment. RDI: respiratory disturbance index; UPPP: uvulopalatopharyngoplasty; RT: radiotherapy; Oct: octreotide; Bro: bromocriptine; Ad: adenomectomy; Ton: tonsillectomy. 
be responsible for failures in treatment of acromegaly (even including octreotide).

It is also of interest that improvement of sleep apnoea may occur using octreotide, even though GH suppression is incomplete. In reviewing the literature, we found two patients with a reduction in RDI below 20 and with a GH level still elevated (but lower than before the treatment with octreotide) $[8,11]$. The RDI of patient No.1 also diminished from 60 to 7 episodes $\cdot \mathrm{h}^{-1}$ after treatment with octreotide, although the GH level was not fully normalized. It is intriguing that "normalization" of SAS in the setting of still elevated GH levels or active disease only occurred when using octreotide. Has octreotide an intrinsic effect on the genesis of apnoeic phenomena? Octreotide is reported to decrease soft tissue swelling in patients with acromegaly [3, 6, 10, 17]. In addition, octreotide, which is a long-acting somatostatin analogue, might have an effect on respiratory control. Somatostatin has inhibitory effects on breathing in animals [18], and decreases chemosensitivity to hypoxaemia in humans [19]. Persons with increased ventilatory responsiveness to hypoxaemia (and hypercapnia) develop apnoea in sleep [20, 21]. Somatostatin decreases the ventilatory response to hypoxaemia and, thus, may normalize breathing during sleep in those patients.

In conclusion, we found in the literature only 10 patients with a polygraphically proven apnoea syndrome with RDI $>20$ before treatment and reversal with RDI $<20$ after treatment of acromegaly. The RDI fell below 20 only in those patients treated with a pituitary adenectomy or with octreotide (although a significant reduction of apnoea was not found in all patients treated in that way). We have now added three cases in which the respiratory disturbance index became lower than 20 after treatment with octreotide. Using octreotide, marked improvement of sleep apnoea (RDI <20) occurred, even when the growth hormone level was not fully suppressed. This raises the intriguing hypothesis that octreotide might have effects on respiratory control or on the upper airway, unrelated to its action in decreasing production of growth hormone by the pituitary.

\section{References}

1. Grunstein RR, Ho KY, Sullivan CE, et al. Sleep apnoea in acromegaly. Ann Intern Med 1991; 115: 527-532.

2. Pekkarinen T, Partinen M, Pelkonen R, et al. Sleep apnoea and daytime sleepiness in acromegaly: relationship to endocrinological factors. Clin Endocrinol 1987; 27: 649-654.

3. Chanson $\mathrm{Ph}$, Timsit J, Benoit O, et al. Rapid improvement in sleep apnoea of acromegaly after short-term treatment with somatostatin analogue SMS 201-995. Lancet 1986; i: 1270-1271.

4. Ziemer DC, Dunlap DB. Relief of sleep apnoea in acromegaly by bromocriptine. Am J Med Sci 1988; 295 : 49-51.

5. Main G, Borsey D, Newton R. Successful reversal of sleep apnoea syndrome following treatment for acromegaly, confirmed by polygraphic studies. Postgrad Med J 1988; 64: 945-946.

6. Esnault $\mathrm{S}$, Merceur $\mathrm{C}$, Kerlan V, et al. Effets à long terme du traitement par SMS 201-995 sur un syndrome d'apnées du sommeil associé à une acromégalie. Neurophysiol Clin 1989; 19: 367-372.

7. O' Hare JA, Abuaisha F, Cotter T. Experiences with octreotide in acromegaly. J Med Sci 1993; 162: 40-42.

8. Grunstein R, Ho K, Sullivan C, et al. Effect of octreotide, a somatostatin analog, on sleep apnoea in patients with acromegaly. Ann Intern Med 1994; 121: 478-483.

9. Mickelson SA, Rosenthal LD, Rock JP, et al. Obstructive sleep apnoea and acromegaly. Otolaryngol Head Neck Surg 1994; 111: 25-30.

10. Rosenow F, Teuter S, Szelies B, et al. Sleep apnoea in acromegaly: prevalence, pathogenesis and therapy (report on two cases). Presse Med 1994; 23: 1203-1208.

11. Leibowitz G, Shapiro M, Salameh M, et al. Improvement of sleep apnoea due to acromegaly during short-term treatment with octreotide. J Intern Med 1994; 236: 231-235.

12. Kalia M, Fuxe K, Agnati L, et al. Somatostatin produces apnea and is localized in medullary respiratory nuclei: a possible possible role in apneic syndromes. Brain Res 1984; 296: 339-344.

13. Rolffe I, Olson L, Saunders N. Long-term nasal CPAP does not ameliorate obstructive sleep apnoea. Aust NZ J Med 1991; 21: 235-238.

14. Sanders MH. Medical therapy for sleep apnea. In: Kryger MH, Roth R, Dement WC (eds). Principles and Practice of Sleep Medicine. 2nd edn. Philadelphia, W.B. Saunders Co. 1994; pp. 678-693.

15. De Boer H, Roelfsema F, Fröhlich M, et al. Plasma growth hormone profiles and sleep: a study of 13 treated patients. Clin Endocrinol 1989; 30: 251-261.

16. Pelttari L, Polo O, Rauhala E, et al. Nocturnal breathing abnormalities in acromegaly after adenomectomy. Clin Endocrinol 1995; 43: 175-182.

17. Bauer W, Briner U, Doepfner W, et al. SMS 201-995: a very potent and selective octapeptide analog of somatostatin with prolonged action. Life Sci 1982; 31: 1133-1140.

18. Yamamoto Y, Runold M, prabhakar N, et al. Somatostatin in control of respiration. Acta Physiol Scand 1988; 134: 529-533.

19. Filuk R, Berezanski D, Anthonissen N. Depression of hypoxic ventilatory response in humans by somatostatin. J Appl Physiol 1988; 65: 1050-1054.

20. Sullivan C, Issa F, Berthon-Jones M, et al. Pathophysiology of sleep apnoea. In: Saunders NA, Sullivan CE, eds. Sleep and Breathing. New York, Marcel Dekker, 1984.

21. Gleeson K, Zwillich C, White D. Chemosensitivity and the ventilatory response to airway obstruction during sleep. J Appl Physiol 1989; 67: 1630-1637. 